\title{
Monitoring the formation of cholesterol oxidation products in model systems using response surface methodology
}

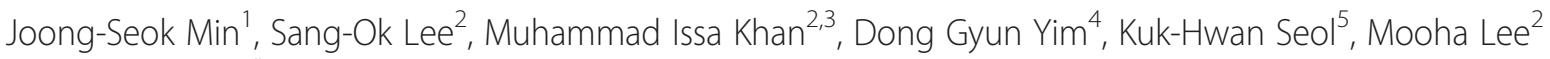
and Cheorun $\mathrm{JO}^{2^{*}}$

\begin{abstract}
Background: Cholesterol oxidation products (COPs) are produced during thermal processing of animal origin foods and are considered to have negative health impacts. The model systems are helpful to understand the impact of various factors on oxidation changes in foods during cooking process.

Methods: The study presented herein investigates the effects of $\mathrm{pH}$, presence of unsaturated fatty acids, and heat on the formation of cholesterol oxidation products (COPs). Two model systems were designed to investigate the formation of cholesterol oxidation products in different lipid environments. The cholesterol oxides produced were quantified using gas chromatography.

Results: The level of cholesterol oxidation products decreased significantly at higher pH (above 5.8) and shorter heating time ( $3 \mathrm{~h}$ ). The presence of unsaturated fatty acids (linoleic and oleic acids) significantly increased the amount of COPs under low-temperature heating conditions $\left(100{ }^{\circ} \mathrm{C}\right.$ and $\left.1 \mathrm{~h}\right)$ but did not affect the production of COPs at higher temperature $\left(150^{\circ} \mathrm{C}\right)$. Increasing the temperature to $200^{\circ} \mathrm{C}$ significantly increased the amount of COPs during the first hour of heating and this amount decreased upon further heating. The most frequently observed COPs in samples were a-epoxide, 20a-hydroxycholesterol, and 25-hydroxycholesterol.
\end{abstract}

Conclusions: In conclusion, pH below 5.8, presence of unsaturated fatty acid, and high cooking temperature $\left(>150^{\circ} \mathrm{C}\right)$ leads to increased production of cholesterol oxidation products.

Keywords: Cooking conditions, pH, Unsaturated fatty acids, COPs

\section{Introduction}

Cholesterol is a biologically important compound that is widely present in animal-derived foods. Storing cholesterol in the presence of oxidants (light, oxygen, and catalysts) leads to the formation of cholesterol oxidation products (COPs). COPs are considered to be more detrimental to arterial cells than is pure cholesterol and are directly linked to atherosclerosis and coronary heart disease [1]. Additionally, COPs inhibit the biosynthesis [2] and dietary uptake [3] of cholesterol. Therefore, COPs are considered to be cytotoxic,

\footnotetext{
* Correspondence: cheorun@snu.ac.kr

${ }^{2}$ Department of Agricultural Biotechnology, Center for Food and Bioconvergence, and Research Institute of Agriculture and Life Science, Seoul National University, Seoul 51-921, Korea

Full list of author information is available at the end of the article
}

mutagenic, and carcinogenic [4]. The main causes of cholesterol oxidation in animal-derived foods are cooking, dehydration, and deep frying [5].

Healthy human plasma contains $12.6 \mathrm{mg} / \mathrm{L}$ of COPs [6] and ingestion of foods containing COPs increases these levels in plasma and leads to deleterious health effects. More than 80 COPs have been identified, and those most commonly found in food are 7-ketocholesterol (7-keto), 6-ketocholesterol (6-keto), 7 $\alpha$-hydroxy-cholesterol (7 $\alpha-\mathrm{OH}), 7 \beta$-hydroxycholesterol $(7 \beta-\mathrm{OH}), 5,6 \alpha$-epoxy-

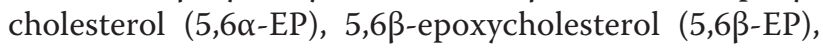
25-hydroxycholesterol (25-OH), 20-hydroxycholesterol $(20-\mathrm{OH})$, and cholestanetriol (triol). COPs are formed when animal-derived foods are subjected to the following processes: heating and cooking [7], dehydration [8], storage [9], and irradiation [10]. 
The major factors that influence the formation of COPs are heat, $\mathrm{pH}$, light, oxygen, water activity, and the presence of unsaturated fatty acids (UFAs). The UFAs in meat are very susceptible to peroxidation, even under mild ambient conditions, and consequently yield both free and peroxy radicals [11]. Therefore, it is reasonable to suspect that oxidation of cholesterol is accelerated in the presence of peroxydized lipids [12]. Saldanha et al. [13] reported a decreased level of polyunsaturated fatty acids (PUFAs) with a decrease in the total amount of cholesterol during the grilling of sardines. The synergistic decrease in the levels of cholesterol and PUFAs provides evidence that cholesterol oxidation is promoted by the oxidation of PUFAs. However, the environmental conditions to promote the production of COPs still need to be determined.

Accordingly, the present study was designed to investigate the effects of $\mathrm{pH}$ and unsaturated fatty acids on the formation of COPs under different heating conditions in model systems.

\section{Materials and methods \\ Reagents and solutions}

Cholesterol, linoleic acid, oleic acid, cholesterol oxide standards (7-keto, 6-keto, $7 \alpha-\mathrm{OH}, 7 \beta-\mathrm{OH}, 5,6 \alpha-\mathrm{EP}, 5,6 \beta-$ $\mathrm{EP}, 25-\mathrm{OH}, 20-\mathrm{OH}$, and triol), butylated hydroxytoluene (BHT), pyridine, and silicic acid (100 mesh) were purchased from Sigma-Aldrich Co., LLC (Seoul, Korea). Bis-[trimethylsilyl]-trifluoroacetamide (BSTFA) + $1 \%$ trimethylchlorosilane (TMCS) was obtained from Supelco (Bellefonte, PA, USA). HPLC grade hexane, ethyl acetate, acetone, methanol, and chloroform, Celite 545, and calcium phosphate $\left(\mathrm{CaHPO}_{4} \cdot 2 \mathrm{H}_{2} \mathrm{O}\right)$ were purchased from Fisher Scientific Co. (Malvern, PA, USA).

\section{Model system-I}

Model system-I was designed with suitable emulsions to assess the influence of $\mathrm{pH}$ on cholesterol oxidation using the method of Miyako et al. [14] which is described in this section. Borate buffer $(0.1 \mathrm{M}, 10 \mathrm{~mL})$ and cholesterol $(50 \mathrm{mg}$ ) were mixed in a vortex mixer (G560, Scientific Industries Inc., NY, USA) for $20 \mathrm{~s}$ and then placed in a sonicator (Braun $\mathrm{GmbH}$, Kronberg, Germany) for $10 \mathrm{~min}$. The $\mathrm{pH}$ of the resulting emulsions was adjusted to 5.8, 6.7, and 7.6 using either $\mathrm{HCl}$ or $\mathrm{NaOH}$. The emulsions $(10 \mathrm{~mL})$ were stored at $4{ }^{\circ} \mathrm{C}$ for $10 \mathrm{~d}$ and then filtered through a Whatman No. 1 (Whatman Inc., Clifton, NJ). BHT $(7.2 \%, 50 \mu \mathrm{L})$ was added to the filtered emulsions to prevent further oxidation during analysis of the COPs. The amounts of COPs were measured using gas chromatography (GC) according to the method described by Lee et al. [10].

\section{Model system-II}

Model system-II was designed to assess the influence of unsaturated fatty acids on cholesterol oxidation. Cholesterol $(50 \mathrm{mg})$ was dissolved in chloroform $(1 \mathrm{~mL})$ and placed in a $10 \mathrm{~mL}$ test tube. The solvent was evaporated under an atmosphere of nitrogen to obtain a thin cholesterol film. Afterwards, cholesterol was mixed with unsaturated fatty acids (linoleic acid or oleic acid) in ratios of $1: 20$ and 1:100, respectively. The mixtures were heated for $1,3,5$, and $10 \mathrm{~h}$ at various temperatures (100, 150 , and $200{ }^{\circ} \mathrm{C}$ ) in an oil bath. After the heat treatments, $\operatorname{BHT}(7.2 \%, 50 \mu \mathrm{L})$ was added to the filtered emulsions to inhibit further oxidation during analysis of the COPs. The amounts of COPs were measured using gas chromatography (GC) according to the method described by Lee et al. [10].

\section{Response surface methodology}

The effects of the heating conditions (heating temperature and heating time) on the production of COPs were monitored using the response surface methodology experiment designed by Gontard et al. [15]. The experimental design consisted of two factors with varying levels that were replicated thrice at the center point [16]. The independent variables, the coded variables, and their levels of interest for this research are presented in Table 1.

\section{Statistical analysis}

Data were analyzed with Statistical Analysis System (SAS) software to evaluate the effects of $\mathrm{pH}$, unsaturated fatty acids, and heating conditions on the formation of COPs. All the experimental procedures were triplicated. The amount of COPs (Y) was subjected to analyze for dependent variables (responses). Means values of triplicate determinations

Table 1 Conditions with different combinations of independent variable used in central composite rotatable second order design for response surface methodology

\begin{tabular}{lllll}
\hline Treatment No. & X1 & X2 & Heating Temperature $(\mathrm{t})$ & Heating Time (T) \\
\hline 1 & -1 & -1 & 100 & 1 \\
2 & -1 & -0.5 & 100 & 3 \\
3 & -1 & -0.1 & 100 & 5 \\
4 & -1 & 1 & 100 & 10 \\
5 & 0 & -1 & 150 & 1 \\
6 & 0 & -0.5 & 150 & 3 \\
7 & 0 & -0.1 & 150 & 5 \\
8 & 0 & 1 & 150 & 10 \\
9 & 1 & -1 & 200 & 1 \\
10 & 1 & -0.5 & 200 & 3 \\
11 & 1 & -0.1 & 200 & 5 \\
12 & 1 & 1 & 200 & 10 \\
\hline
\end{tabular}


were analyzed to fit the following second-order polynomial models to $Y$ variables [15].

$$
\mathrm{Y}=\mathrm{b}_{0}+\mathrm{b}_{1} \mathrm{X}_{1}+\mathrm{b}_{2} \mathrm{X}_{2}+\mathrm{b}_{12} \mathrm{X}_{1} \mathrm{X}_{2}+\mathrm{b}_{11} \mathrm{X}_{1}{ }^{2}+\mathrm{b}_{22} \mathrm{X}_{2}{ }^{2}
$$

Where $\mathrm{X}_{1}$ and $X_{2}$ correspond to independent variables (heating time and temperature) and $b_{n}$ represent corresponding regression coefficient. Response surface and contour plots were developed using fitted polynomial equations.

\section{Results and discussion}

\section{Effects of $\mathrm{pH}$ on the formation of COPs}

Cholesterol oxidation products (COPs), or oxysterols, have received increasing attention for the following biological roles: diagnostic biomarker of oxidative stress, intermediates in bile acid biosynthesis, messengers for cell signaling, and cholesterol transport [17]. Cholesterol is more susceptible to autoxidation in the liquid state [18] and is oxidized by both enzymatic and non-enzymatic mechanisms [17]. The results illustrating the impact of $\mathrm{pH}$ on the formation of COPs are depicted in Table 2. Three main cholesterol oxidation products were detected in samples stored for $10 \mathrm{~d}$ at $4{ }^{\circ} \mathrm{C}: 20 \alpha-\mathrm{OH}$, $25-\mathrm{OH}$, and $\alpha$-epoxide. Triol was additionally found in control samples. In the current model system, cholesterol was autoxidized by a non-enzymatic mechanism. Results from statistical analysis studies showed that there were no significant differences observed between the $\mathrm{pH}$ treatments (5.8 to 7.6), but a significant difference was observed between the control sample and the $\mathrm{pH}$-treated samples. The control sample (cholesterol without borate buffer) exhibited higher levels of $20 \alpha-\mathrm{OH}, 25-\mathrm{OH}$, and $\alpha$-epoxide than samples with borate buffer. It is evident from these results that a $\mathrm{pH}$ range between 5.8 and 7.6 does not affect the oxidation of cholesterol at refrigeration temperatures. Meanwhile, lower $\mathrm{pH}$ levels (5.6 and 5.8) of the oxidation medium promote increased lipid oxidation [19]; accelerated lipid oxidation was observed in carcasses exposed to $\mathrm{pH}$ levels below 5.8 [20].
The pronounced discoloration of carcasses during chilled storage below pH 5.8 may result from higher rates of oxymyoglobin oxidation to produce metmyoglobin [21]. Cholesterol oxidation in meat and meat products has been observed during frozen storage [22] as well as during heating [18]. Kowale et al. [23] observed faster changes in cholesterol oxides for refrigerated mutton compared to frozen mutton; this observation was attributed to the presence of free radicals, which resulted from the oxidation of UFAs.

\section{Effects of linoleic and oleic acids on the formation of COPs}

The focus of this study was to assess the impact of heating conditions and the addition of unsaturated fatty acids on COP production in model systems. Samples were heated at 100,150 , and $200{ }^{\circ} \mathrm{C}$ for $1,3,5,7$ and $10 \mathrm{~h}$; some samples did not contain added unsaturated fatty acids while others contained cholesterol with either linoleic or oleic acid in ratios of 1:20 and 1:100, respectively. The results regarding the changes in the COP contents $(\mathrm{mg})$ of samples with or without linoleic or oleic acid heated at $100{ }^{\circ} \mathrm{C}$ for 1 to $10 \mathrm{~h}$ are shown in Table 3 . The COPs $25-\mathrm{OH}, \alpha$-epoxide, 7 -keto were produced when cholesterol alone was heated at $100{ }^{\circ} \mathrm{C}$ for $1 \mathrm{~h}$. $7 \beta$ $\mathrm{OH}$ was detected after 3 and $5 \mathrm{~h}$ of heating, while $20 \alpha-$ $\mathrm{OH}$ was detected after 3 and $10 \mathrm{~h}$ of heating. However, the COPs $\alpha$-epoxide and 7-keto were not detected after $5 \mathrm{~h}$ of heating. The amounts of $7 \beta-\mathrm{OH}$ were significantly higher in samples $\mathrm{CL}_{1}, \mathrm{CL}_{2}, \mathrm{CO}_{1}$ and $\mathrm{CO}_{2}$ after heating for $1 \mathrm{~h}$ compared to other heating times $(3,5,7$, and $10 \mathrm{~h}$ ), while small amounts of $7 \beta-\mathrm{OH}$ were detected in control samples only after heating for 3 and $5 \mathrm{~h}$ (Table 3). Chien et al. [24] studied the kinetics of cholesterol oxidation during heating by selecting five major COPs namely $7-\mathrm{OOH}$ ( $7 \alpha-$ and $7 \beta$-hydroperoxycholesterol), 7ketocholesterol, 7-OH ( $7 \alpha$ - and $7 \beta$-hydroxycholesterol), 5, 6-epoxy (5, $6 \alpha$ - and 5, $6 \beta$-epoxycholesterol), and triol ( $5 \alpha$-cholestane-3 $\beta, 5,6 \beta$-triol). They observed that

Table 2 The contents of COPs under different $\mathrm{pH}$ condition after storage at $4{ }^{\circ} \mathrm{C}$ for 10 days

\begin{tabular}{|c|c|c|c|c|}
\hline Treatment COPs (mg) & Control & $\mathrm{pH} 5.8$ & $\mathrm{pH} 6.7$ & $\mathrm{pH} 7.6$ \\
\hline $7 \beta-\mathrm{OH}$ & $\mathrm{Nd}$ & nd & nd & nd \\
\hline $20 \mathrm{a}-\mathrm{OH}^{*}$ & $0.51 \pm 0.07^{\mathrm{a}}$ & $0.43 \pm 0.02^{\mathrm{ab}}$ & $0.37 \pm 0.01^{b}$ & $0.38 \pm 0.06^{\mathrm{b}}$ \\
\hline $25-\mathrm{OH}^{* * *}$ & $0.13 \pm 0.01^{a}$ & $0.07 \pm 0.01^{b}$ & $0.06 \pm 0.00^{b}$ & $0.06 \pm 0.02^{b}$ \\
\hline Triol $^{* * *}$ & $0.02 \pm 0.00^{\mathrm{a}}$ & n.d. ${ }^{b}$ & n.d. ${ }^{\text {b }}$ & n.d. ${ }^{\mathrm{b}}$ \\
\hline a-epoxide & $0.04 \pm 0.01$ & $0.03 \pm 0.01$ & $0.03 \pm 0.01$ & $0.03 \pm 0.00$ \\
\hline 7-keto & $\mathrm{Nd}$ & nd & nd & nd \\
\hline Total amount of COPs/cholesterol (\%) ${ }^{* *}$ & $1.40 \pm 0.17^{\mathrm{a}}$ & $1.06 \pm 0.08^{b}$ & $0.91 \pm 0.05^{b}$ & $0.95 \pm 0.16^{b}$ \\
\hline
\end{tabular}

$7 \beta-\mathrm{OH} 7 \beta$-hydroxycholesterol, 20a-OH 7a-hydroxy-cholesterol, 25-OH 25-hydroxycholesterol, Triol Cholestanetriol, a-epoxide 5,6a-epoxycholesterol,

7-keto 7-ketocholesterol

$\stackrel{*}{*} P<0.05,{ }^{* *}: P<0.01,{ }^{* * *}: P<0.001$

a, b Means \pm SE with different superscript in the same row differ significantly 
Table 3 The changes in COPs contents $(\mathrm{mg})$ in cholesterol with or without unsaturated fatty acids during heating at $100{ }^{\circ} \mathrm{C}$

\begin{tabular}{|c|c|c|c|c|c|c|c|c|}
\hline Treat & Hour & $7 \beta-\mathrm{OH}^{* * *}$ & $20 \mathrm{a}-\mathrm{OH}^{* * *}$ & $25-\mathrm{OH}^{* * *}$ & Triol $^{* * *}$ & a-epoxide $^{* * *}$ & $7-$ keto $^{* * *}$ & Total amount of COPs \\
\hline \multirow[t]{4}{*}{$\bar{C}$} & 1 & n.d. $^{d}$ & n.d. ${ }^{f}$ & $0.07 \pm 0.00^{b c}$ & n.d. $^{d}$ & $0.02 \pm 0.01^{\text {ghi }}$ & $0.03 \pm 0.00^{b c}$ & $0.11 \pm 0.002^{e f}$ \\
\hline & 3 & $0.08 \pm 0.01^{d}$ & $0.11 \pm 0.01^{\mathrm{e}}$ & $0.05 \pm 0.01^{\mathrm{bcd}}$ & n.d. ${ }^{d}$ & $0.02 \pm 0.00^{g h i}$ & $0.05 \pm 0.00^{b}$ & $0.31 \pm 0.03^{\mathrm{ef}}$ \\
\hline & 5 & $0.01 \pm 0.00^{d}$ & n.d. ${ }^{f}$ & $0.01 \pm 0.00^{f}$ & n.d. ${ }^{d}$ & n.d. ${ }^{i}$ & n.d. ${ }^{c}$ & $0.01 \pm 0.001^{f}$ \\
\hline & 10 & n.d. ${ }^{d}$ & $0.02 \pm 0.00^{f}$ & $0.01 \pm 0.00^{e f}$ & n.d. ${ }^{d}$ & n.d. ${ }^{i}$ & n.d. ${ }^{c}$ & $0.03 \pm 0.01^{f}$ \\
\hline $\mathrm{CL}_{1}$ & 1 & $1.47 \pm 0.18^{b}$ & $0.21 \pm 0.03^{c}$ & $0.06 \pm 0.01^{b c}$ & n.d. ${ }^{d}$ & $0.02 \pm 0.00^{f g h}$ & n.d. ${ }^{c}$ & $1.76 \pm 0.22^{b}$ \\
\hline \multirow[t]{3}{*}{$(1: 20)$} & 3 & n.d. ${ }^{d}$ & $0.02 \pm 0.00^{f}$ & $0.003 \pm 0.00^{f}$ & n.d. ${ }^{d}$ & $0.13 \pm 0.01^{b}$ & n.d. ${ }^{c}$ & $0.15 \pm 0.01^{\mathrm{ef}}$ \\
\hline & 5 & n.d. ${ }^{d}$ & $0.03 \pm 0.01^{f}$ & $0.01 \pm 0.00^{f}$ & n.d. ${ }^{d}$ & $0.16 \pm 0.02^{a}$ & n.d. ${ }^{c}$ & $0.19 \pm 0.03^{\mathrm{ef}}$ \\
\hline & 10 & n.d. ${ }^{d}$ & $0.26 \pm 0.08^{b}$ & $0.06 \pm 0.01^{b c}$ & n.d. ${ }^{d}$ & $0.03 \pm 0.01^{\text {efgh }}$ & $0.35 \pm 0.09^{a}$ & $0.69 \pm 0.18^{d}$ \\
\hline $\mathrm{CL}_{2}$ & 1 & $1.29 \pm 0.08^{b}$ & $0.17 \pm 0.01^{d}$ & $0.08 \pm 0.01^{b}$ & $0.02 \pm 0.00^{\mathrm{a}}$ & $0.03 \pm 0.00^{\text {defg }}$ & $0.06 \pm 0.00^{b}$ & $1.64 \pm 0.10^{b}$ \\
\hline \multirow[t]{3}{*}{$(1: 100)$} & 3 & n.d. ${ }^{d}$ & $0.002 \pm 0.00^{f}$ & $0.16 \pm 0.07^{\mathrm{a}}$ & $0.01 \pm 0.00^{b}$ & $0.05 \pm 0.01^{c d}$ & n.d. ${ }^{c}$ & $0.22 \pm 0.09^{e f}$ \\
\hline & 5 & $0.01 \pm 0.00^{d}$ & $0.01 \pm 0.00^{f}$ & $0.004 \pm 0.00^{f}$ & $0.01 \pm 0.00^{c}$ & n.d..$^{i}$ & n.d. ${ }^{c}$ & $0.04 \pm 0.004^{f}$ \\
\hline & 10 & n.d. ${ }^{d}$ & $0.01 \pm 0.00^{f}$ & $0.002 \pm 0.00^{f}$ & n.d. ${ }^{d}$ & n.d. ${ }^{i}$ & n.d. ${ }^{c}$ & $0.01 \pm 0.002^{f}$ \\
\hline $\mathrm{CO}_{1}$ & 1 & $0.66 \pm 0.03^{c}$ & $0.29 \pm 002^{b}$ & $0.04 \pm 0.00^{\text {cde }}$ & n.d. ${ }^{d}$ & $0.01 \pm 0.00^{\text {hi }}$ & n.d. ${ }^{c}$ & $1.01 \pm 0.05^{c}$ \\
\hline \multirow[t]{3}{*}{$(1: 20)$} & 3 & n.d. ${ }^{d}$ & $0.0003 \pm 0.00^{f}$ & $0.01 \pm 0.00^{f}$ & n.d. ${ }^{d}$ & $0.04 \pm 0.00^{\mathrm{def}}$ & n.d. ${ }^{c}$ & $0.05 \pm 0.003^{f}$ \\
\hline & 5 & n.d. ${ }^{d}$ & $0.02 \pm 0.00^{f}$ & $0.01 \pm 0.00^{f}$ & n.d. ${ }^{d}$ & $0.12 \pm 0.02^{b}$ & n.d. ${ }^{c}$ & $0.15 \pm 0.03^{\mathrm{ef}}$ \\
\hline & 10 & n.d. ${ }^{d}$ & $0.36 \pm 0.05^{\mathrm{a}}$ & $0.02 \pm 0.00^{\mathrm{def}}$ & n.d. ${ }^{d}$ & $0.03 \pm 0.00^{\text {defg }}$ & n.d. ${ }^{c}$ & $0.42 \pm 0.06^{\text {de }}$ \\
\hline $\mathrm{CO}_{2}$ & 1 & $3.79 \pm 0.63^{\mathrm{a}}$ & $0.18 \pm 0.02^{\mathrm{cd}}$ & $0.06 \pm 0.01^{b c}$ & $0.02 \pm 0.00^{a}$ & $0.03 \pm 0.00^{\mathrm{def}}$ & $0.05 \pm 0.00^{b}$ & $4.12 \pm 0.67^{a}$ \\
\hline \multirow[t]{3}{*}{$(1: 100)$} & 3 & n.d. ${ }^{d}$ & $0.004 \pm 0.00^{f}$ & $0.006 \pm 0.00^{f}$ & n.d. ${ }^{d}$ & $0.06 \pm 0.03^{c}$ & n.d. ${ }^{c}$ & $0.07 \pm 0.03^{f}$ \\
\hline & 5 & n.d. ${ }^{d}$ & $0.01 \pm 0.00^{f}$ & $0.003 \pm 0.00^{f}$ & n.d. ${ }^{d}$ & $0.04 \pm 0.00^{\text {de }}$ & n.d. ${ }^{c}$ & $0.05 \pm 0.01^{f}$ \\
\hline & 10 & n.d. ${ }^{d}$ & $0.01 \pm 0.00^{f}$ & n.d. ${ }^{f}$ & n.d. ${ }^{d}$ & n.d. & n.d. ${ }^{c}$ & $0.01 \pm 0.001^{f}$ \\
\hline
\end{tabular}

$C$ cholesterol $(50 \mathrm{mg}), L$ linoleic acid, O: oleic acid, $C L_{1}$ cholesterol $(50 \mathrm{mg}):$ linoleic acid $(1 \mathrm{~g})=1: 20, C L_{2}$ cholesterol $(50 \mathrm{mg}):$ linoleic acid $(5 \mathrm{~g})=1: 100, C O_{1}$ cholesterol $(50 \mathrm{mg})$ : oleic acid $(1 \mathrm{~g})=1: 20, \mathrm{CO}_{2}$ cholesterol $(50 \mathrm{mg})$ : oleic acid $(5 \mathrm{~g})=1: 100$

$7 \beta-\mathrm{OH} 7 \beta$-hydroxycholesterol, 20a-OH 7a-hydroxy-cholesterol, 25-OH 25-hydroxycholesterol, Triol Cholestanetriol, a-epoxide 5,6a-epoxycholesterol,

7-keto: 7-ketocholesterol

${ }^{* * *} P<0.001$. n.d not detected

${ }^{a-i}$ Means \pm SE with different superscript in the same column differ significantly

concentration of COPs increased with the increase in heating time.

The addition of unsaturated fatty acids significantly affected the production of $20 \alpha-\mathrm{OH}$ and the greatest amount $(0.36 \mathrm{mg})$ was observed in sample $\mathrm{CO}_{1}$ after $10 \mathrm{~h}$ of heating. In the control sample (cholesterol only), the greatest amount of COP 25-OH was detected after $1 \mathrm{~h}$ of heating; the tendency of the control sample to produce $25-\mathrm{OH}$ was similar to that of $\mathrm{CL}_{1}, \mathrm{CO}_{1}$ and $\mathrm{CO}_{2}$. Meanwhile, the greatest amount of $25-\mathrm{OH}$ in $\mathrm{CL}_{2}$ was produced after $3 \mathrm{~h}$ of heating. The greatest amounts of triol were detected in $\mathrm{CL}_{2}$ and $\mathrm{CO}_{2}$ after heating for $1 \mathrm{~h}$, yet triol was not detected in $\mathrm{C}, \mathrm{CL}_{1}$ and $\mathrm{CO}_{1}$. The concentration of $\alpha$ epoxide varied significantly from ND to $0.16 \mathrm{mg}$. The COP $\alpha$-epoxide was not detected in $\mathrm{C}$ ( 5 and $10 \mathrm{~h}$ of heating), $\mathrm{CL}_{2}$ (5 and $10 \mathrm{~h}$ of heating), or $\mathrm{CO}_{2}$ (10 h of heating). Meanwhile, the greatest amount of $\alpha$-epoxide $(0.16 \mathrm{mg})$ was observed in $\mathrm{CL}_{1}$ after $5 \mathrm{~h}$ heating. The COP 7-keto was found in $\mathrm{C}, \mathrm{CL}_{2}$ and $\mathrm{CO}_{2}$ after heating for $1 \mathrm{~h}$, but it was not observed in $\mathrm{CL}_{1}$ and $\mathrm{CO}_{1}$. Heating for longer time periods did not result in additional production of keto in either $\mathrm{C}$ (after $5 \mathrm{~h}$ ) or $\mathrm{CL}_{2}$ and $\mathrm{CO}_{2}$ (after $3 \mathrm{~h}$ ), yet a higher concentration of keto $(0.35 \mathrm{mg})$ was detected in
$\mathrm{CL}_{1}$ after $10 \mathrm{~h}$ of heating. It has been reported that heating cholesterol in the presence of oxygen proceeds to oxidation and degradation [25]. The two major routes of oxidation are C-7 oxidation and epoxidation. The oxidation reaction is initiated by the attack of free radicals on cholesterol, which produces 7-OOH according to a secondorder pathway; the $7-\mathrm{OOH}$ formation rate equation was described in a report by Chien et al. [25]. In the current study, the presence of UFAs (linoleic and oleic acid) in the reaction medium presumably allows the radical-mediated peroxidation reactions to proceed [17].

The results regarding the production of COPs in cholesterol samples heated at $150{ }^{\circ} \mathrm{C}$ for 1 to $10 \mathrm{~h}$ with or without UFAs (linoleic and oleic acid) are presented in Table 4. The cholesterol samples without UFAs (control) produced the COPs $20 \alpha-\mathrm{OH}, 25-\mathrm{OH}, \alpha$-epoxide, and 7 keto after heating for $1 \mathrm{~h}$. Triol was not detected when samples were heated longer than $1 \mathrm{~h}$, while $20 \alpha-\mathrm{OH}, 25-$ $\mathrm{OH}, \alpha$-epoxide, and 7-keto were produced when samples were subjected to longer heating times (up to $10 \mathrm{~h}$ ). The

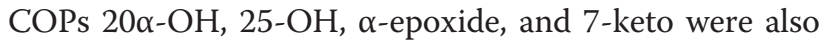
found in samples with UFAs $\left(\mathrm{CL}_{1}, \mathrm{CL}_{2}, \mathrm{CO}_{1}\right.$ and $\left.\mathrm{CO}_{2}\right)$ after heating for $1 \mathrm{~h}$, as well as $10 \mathrm{~h}$. In most samples, 
Table 4 The changes in COPs contents $(\mathrm{mg})$ in cholesterol with or without unsaturated fatty acids during heating at $150^{\circ} \mathrm{C}$

\begin{tabular}{|c|c|c|c|c|c|c|c|c|}
\hline Treat & Hour & $7 \beta-\mathrm{OH}^{* * *}$ & $20 \mathrm{a}-\mathrm{OH}^{* * *}$ & $25-\mathrm{OH}^{* * *}$ & Triol $^{* * *}$ & a-epoxide $^{* * *}$ & $7-$ keto $^{* * *}$ & Total amount of COPs \\
\hline \multirow[t]{4}{*}{$\bar{C}$} & 1 & n.d. $^{d}$ & $0.25 \pm 0.01^{b}$ & $0.06 \pm 0.00^{\text {ef }}$ & $0.55 \pm 0.05^{a}$ & $0.46 \pm 0.01^{a}$ & $1.29 \pm 0.16^{c}$ & $2.60 \pm 0.22^{a}$ \\
\hline & 3 & n.d. ${ }^{d}$ & n.d.! & $0.10 \pm 0.01^{b c}$ & n.d. ${ }^{b}$ & $0.46 \pm 0.02^{\mathrm{a}}$ & $1.80 \pm 0.01^{\mathrm{a}}$ & $2.36 \pm 0.04^{a}$ \\
\hline & 5 & n.d. ${ }^{d}$ & $0.16 \pm 0.02^{\text {de }}$ & $0.10 \pm 0.00^{b}$ & n.d. ${ }^{b}$ & $0.25 \pm 0.06^{b}$ & $1.19 \pm 0.33^{c d}$ & $1.71 \pm 0.42^{b c}$ \\
\hline & 10 & n.d. ${ }^{d}$ & $0.09 \pm 0.06^{g h}$ & $0.10 \pm 0.04^{b}$ & n.d. ${ }^{b}$ & $0.25 \pm 0.08^{b}$ & $1.48 \pm 0.11^{b}$ & $1.92 \pm 0.30^{b}$ \\
\hline $\mathrm{CL}_{1}$ & 1 & n.d. ${ }^{d}$ & $0.27 \pm 0.01^{b}$ & $0.10 \pm 0.02^{\mathrm{bc}}$ & n.d. ${ }^{b}$ & $0.04 \pm 0.01^{\mathrm{efgh}}$ & $0.19 \pm 0.02^{\mathrm{ef}}$ & $0.60 \pm 0.05^{d}$ \\
\hline \multirow[t]{3}{*}{$(1: 20)$} & 3 & n.d. ${ }^{d}$ & $0.11 \pm 0.03^{f g}$ & $0.03 \pm 0.01^{g h i}$ & n.d. ${ }^{b}$ & $0.10 \pm 0.02^{c d}$ & $0.15 \pm 0.04^{f}$ & $0.39 \pm 0.09^{\text {de }}$ \\
\hline & 5 & n.d. ${ }^{d}$ & $0.07 \pm 0.02^{h i}$ & $0.02 \pm 0.00^{\text {ghij }}$ & n.d. ${ }^{b}$ & $0.05 \pm 0.01^{\text {efg }}$ & $0.10 \pm 0.01^{f}$ & $0.24 \pm 0.03^{\text {de }}$ \\
\hline & 10 & $2.34 \pm 0.60^{\mathrm{a}}$ & $0.02 \pm 0.00^{\mathrm{jkl}}$ & $0.004 \pm 0.00^{J}$ & n.d. ${ }^{b}$ & $0.06 \pm 0.02^{\text {def }}$ & n.d. ${ }^{f}$ & $2.45 \pm 0.62^{\mathrm{a}}$ \\
\hline $\mathrm{CL}_{2}$ & 1 & n.d. ${ }^{d}$ & $0.17 \pm 0.01^{c d}$ & $0.08 \pm 0.01^{\mathrm{bcd}}$ & n.d. ${ }^{b}$ & $0.02 \pm 0.00^{\mathrm{fgh}}$ & $0.12 \pm 0.04^{f}$ & $0.40 \pm 0.05^{\text {de }}$ \\
\hline \multirow[t]{3}{*}{$(1: 100)$} & 3 & n.d. ${ }^{d}$ & $0.11 \pm 0.01^{\mathrm{fg}}$ & $0.08 \pm 0.01^{\text {cde }}$ & n.d. ${ }^{b}$ & $0.03 \pm 0.00^{\mathrm{fgh}}$ & $0.13 \pm 0.01^{f}$ & $0.35 \pm 0.03^{\mathrm{de}}$ \\
\hline & 5 & n.d. ${ }^{D}$ & $0.05 \pm 0.01^{\mathrm{ij}}$ & $0.02 \pm 0.00^{\mathrm{hij}}$ & n.d. ${ }^{b}$ & $0.02 \pm 0.01^{\mathrm{fgh}}$ & $0.04 \pm 0.01^{f}$ & $0.13 \pm 0.03^{\text {de }}$ \\
\hline & 10 & $1.40 \pm 0.21^{b}$ & $0.01 \pm 0.00^{\mathrm{kl}}$ & $0.01 \pm 0.00^{i j}$ & n.d. ${ }^{b}$ & $0.04 \pm 0.01^{\mathrm{fgh}}$ & $0.04 \pm 0.02^{f}$ & $1.50 \pm 0.25^{b c}$ \\
\hline $\mathrm{CO}_{1}$ & 1 & n.d. ${ }^{d}$ & $0.37 \pm 0.02^{\mathrm{a}}$ & $0.06 \pm 0.01^{e^{e f}}$ & n.d. ${ }^{b}$ & $0.02 \pm 0.01^{\mathrm{fgh}}$ & $0.08 \pm 0.01^{f}$ & $0.53 \pm 0.04^{\text {de }}$ \\
\hline \multirow[t]{3}{*}{$(1: 20)$} & 3 & n.d. ${ }^{d}$ & $0.13 \pm 0.01^{\mathrm{ef}}$ & $0.04 \pm 0.01^{f g}$ & n.d. ${ }^{b}$ & $0.11 \pm 0.01^{c}$ & n.d. ${ }^{f}$ & $0.29 \pm 0.04^{\mathrm{de}}$ \\
\hline & 5 & n.d. ${ }^{d}$ & $0.04 \pm 0.00^{\mathrm{ijk}}$ & $0.03 \pm 0.01^{\mathrm{ghi}}$ & n.d. ${ }^{b}$ & $0.09 \pm 0.02^{\text {cde }}$ & n.d..$^{f}$ & $0.16 \pm 0.03^{\mathrm{de}}$ \\
\hline & 10 & $1.49 \pm 0.38^{b}$ & $0.0003 \pm 0.00^{1}$ & $0.009 \pm 0.00^{i j}$ & n.d. ${ }^{b}$ & $0.04 \pm 0.01^{\mathrm{fgh}}$ & $1.06 \pm 0.17^{d}$ & $2.60 \pm 0.56^{a}$ \\
\hline $\mathrm{CO}_{2}$ & 1 & n.d. ${ }^{d}$ & $0.20 \pm 0.02^{c}$ & $0.07 \pm 0.02^{\mathrm{de}}$ & n.d. ${ }^{b}$ & $0.03 \pm 0.01^{\mathrm{fgh}}$ & $0.07 \pm 0.00^{f}$ & $0.36 \pm 0.04^{\text {de }}$ \\
\hline \multirow[t]{3}{*}{$(1: 100)$} & 3 & n.d. ${ }^{d}$ & $0.10 \pm 0.01^{\mathrm{fg}}$ & $0.03 \pm 0.01^{\mathrm{fgh}}$ & n.d. ${ }^{b}$ & $0.01 \pm 0.01^{\text {gh }}$ & $0.05 \pm 0.02^{f}$ & $0.20 \pm 0.05^{\text {de }}$ \\
\hline & 5 & n.d. ${ }^{d}$ & $0.04 \pm 0.00^{\mathrm{ijkl}}$ & $0.02 \pm 0.00^{\text {ghij }}$ & n.d. ${ }^{b}$ & n.d. ${ }^{\text {h }}$ & n.d..$^{f}$ & $0.06 \pm 0.01^{\mathrm{e}}$ \\
\hline & 10 & $0.84 \pm 0.30^{c}$ & $0.01 \pm 0.00^{k 1}$ & $0.17 \pm 0.01^{a}$ & n.d. ${ }^{b}$ & $0.02 \pm 0.00^{f g h}$ & $0.35 \pm 0.11^{\mathrm{e}}$ & $1.38 \pm 0.42^{c}$ \\
\hline
\end{tabular}

$C$ cholesterol $(50 \mathrm{mg}), L$ linoleic acid, O: oleic acid, $C L_{1}$ cholesterol $(50 \mathrm{mg})$ : linoleic acid $(1 \mathrm{~g})=1: 20, C L_{2}$ cholesterol $(50 \mathrm{mg}):$ linoleic acid $(5 \mathrm{~g})=1: 100, C \mathrm{O}_{1}$ cholesterol $(50 \mathrm{mg})$ : oleic acid $(1 \mathrm{~g})=1: 20, \mathrm{CO}_{2}$ cholesterol $(50 \mathrm{mg})$ : oleic acid $(5 \mathrm{~g})=1: 100$

$7 \beta-\mathrm{OH} 7 \beta$-hydroxycholesterol, 20a-OH 7a-hydroxy-cholesterol, 25-OH 25-hydroxycholesterol, Triol Cholestanetriol, a-epoxide 5,6a-epoxycholesterol, 7-keto 7-ketocholesterol

${ }^{* * *} P<0.001$. n.d not detected

${ }^{a-1}$ Means \pm SE with different superscript in the same column differ significantly

the highest COP production was observed after heating for $1 \mathrm{~h}$. Chien et al. [25] observed a sharp decrease in cholesterol between 1.5 to 6 min of heating, which resulted in increased COP production, while prolonged heating resulted in a gradual decrease in cholesterol content. The residual percentage of cholesterol was $33.3 \%$ after $30 \mathrm{~min}$ of heating [25] and greater losses were observed after $60 \mathrm{~min}(50.2 \%)$ and $90 \mathrm{~min}(63.8 \%)$ of heating [18]. These results suggest that the chances of cholesterol oxidation remain at $33.3 \%$ of the initial level after 30 min of heating. Similarly, Saldanha et al. [13] reported a decrease in cholesterol content from 342 to $282 \mathrm{mg} / 100 \mathrm{~g}$ when a fresh sardine was grilled at $165^{\circ} \mathrm{C}$.

The presence of either linoleic or oleic acid in the reaction medium produced interesting data, which are presented in Table 4. The presence of UFAs (linoleic and oleic acid) induced cholesterol to produce $7 \beta-O H$ after $10 \mathrm{~h}$ of heating at $150{ }^{\circ} \mathrm{C}$, and this did not proceed in the absence of UFAs. Further, the content of $7 \beta-\mathrm{OH}$ was higher in samples with added linoleic acid, $\mathrm{CL}_{1}$ (2.34 $\mathrm{mg}$ ) and $\mathrm{CL}_{2}(1.40 \mathrm{mg})$, than in samples with added oleic acid, $\mathrm{CO}_{1}(1.49 \mathrm{mg})$ and $\mathrm{CO}_{2}(0.84 \mathrm{mg})$. These results are attributed to the different number of double bonds in linoleic acid (18:2) and oleic acid (18:1), which accelerate the oxidation of cholesterol. Higher levels of $20 \alpha-\mathrm{OH}$ were observed in samples containing all combinations of UFAs and cholesterol when heated for $1 \mathrm{~h}$ at $150{ }^{\circ} \mathrm{C}$. The total amounts of COPs after heating at $150{ }^{\circ} \mathrm{C}$ were higher in the control samples than in those with unsaturated fatty acids. This trend of COP production at $150{ }^{\circ} \mathrm{C}$ was different from samples heated at $100{ }^{\circ} \mathrm{C}$, in which the addition of UFAs increased the total amounts of COPs.

The data shown in Table 5 describe the change in COP production in samples with or without UFAs (linoleic and oleic acid) heated at $200{ }^{\circ} \mathrm{C}$ for 1 to $10 \mathrm{~h}$. The $\mathrm{COP} 7 \beta-\mathrm{OH}$ was not detected in control samples (cholesterol) after heating at $200{ }^{\circ} \mathrm{C}$ for $1 \mathrm{~h}$, while samples with added UFAs (linoleic and oleic acid) exhibited the highest levels of $7 \beta-\mathrm{OH}$ after heating at $200{ }^{\circ} \mathrm{C}$ for $1 \mathrm{~h}$. Longer heating times $(3,5,7$ and $10 \mathrm{~h})$ resulted in decreased production of $7 \beta-\mathrm{OH}$. The COP triol was detected in samples containing linoleic acid $\left(\mathrm{CL}_{1}\right.$ and $\left.\mathrm{CL}_{2}\right)$ but not in the control sample or in the samples containing oleic acid. The control sample (C) had a significantly higher content of 7-keto than other samples subjected to 
Table 5 The changes in COPs contents $(\mathrm{mg})$ in cholesterol with or without unsaturated fatty acids during heating at $200{ }^{\circ} \mathrm{C}$

\begin{tabular}{|c|c|c|c|c|c|c|c|c|}
\hline Treat & Hour & $7 \beta-\mathrm{OH}^{* * *}$ & $20 \mathrm{a}-\mathrm{OH}^{* * *}$ & $25-\mathrm{OH}^{* * *}$ & Triol $^{* * *}$ & a-epoxide $^{* * *}$ & $7-$ keto $^{* * *}$ & Total amount of COPs \\
\hline \multirow[t]{4}{*}{$C$} & 1 & n.d. ${ }^{e}$ & $0.18 \pm 0.01^{a}$ & $0.10 \pm 0.02^{b c}$ & n.d. ${ }^{c}$ & $0.17 \pm 0.01^{a}$ & $0.88 \pm 0.12^{b c}$ & $1.33 \pm 0.16^{\mathrm{def}}$ \\
\hline & 3 & n.d. ${ }^{e}$ & $0.18 \pm 0.01^{\mathrm{a}}$ & $0.09 \pm 0.01^{c d}$ & n.d. ${ }^{c}$ & $0.11 \pm 0.02^{b c}$ & $0.94 \pm 0.17^{b}$ & $1.32 \pm 0.21^{\text {def }}$ \\
\hline & 5 & n.d. ${ }^{e}$ & $0.08 \pm 0.03^{b}$ & $0.08 \pm 0.01^{e}$ & n.d. ${ }^{c}$ & $0.12 \pm 0.03^{b}$ & $1.10 \pm 0.11^{\mathrm{a}}$ & $1.38 \pm 0.17^{\mathrm{def}}$ \\
\hline & 10 & n.d. ${ }^{e}$ & $0.03 \pm 0.01^{e}$ & $0.06 \pm 0.01^{e}$ & n.d. ${ }^{c}$ & $0.09 \pm 0.03^{\mathrm{bcd}}$ & $0.82 \pm 0.08^{b c}$ & $1.00 \pm 0.12^{\mathrm{efg}}$ \\
\hline $\mathrm{CL}_{1}$ & 1 & $5.75 \pm 0.40^{b}$ & $0.05 \pm 0.01^{c}$ & $0.02 \pm 0.00^{f g}$ & n.d. ${ }^{c}$ & $0.08 \pm 0.04^{\text {cdef }}$ & $0.09 \pm 0.03^{e f}$ & $5.99 \pm 0.48^{b}$ \\
\hline \multirow[t]{3}{*}{$(1: 20)$} & 3 & $0.55 \pm 0.02^{\text {de }}$ & $0.002 \pm 0.00^{F}$ & $0.08 \pm 0.02^{\mathrm{de}}$ & n.d. ${ }^{c}$ & $0.10 \pm 0.06^{b c}$ & $0.10 \pm 0.02^{e f}$ & $0.83 \pm 0.12^{\text {efgh }}$ \\
\hline & 5 & $0.24 \pm 0.02^{\text {de }}$ & n.d. ${ }^{f}$ & $0.10 \pm 0.01^{b c}$ & n.d. ${ }^{c}$ & $0.18 \pm 0.02^{a}$ & $0.20 \pm 0.09^{e}$ & $0.72 \pm 0.14^{\mathrm{fgh}}$ \\
\hline & 10 & $0.18 \pm 0.04^{\text {de }}$ & n.d. ${ }^{f}$ & $0.11 \pm 0.01^{\mathrm{ab}}$ & $0.02 \pm 0.01^{\mathrm{b}}$ & $0.12 \pm 0.02^{b}$ & $0.11 \pm 0.01^{\text {ef }}$ & $0.54 \pm 0.08^{g h}$ \\
\hline $\mathrm{CL}_{2}$ & 1 & $3.33 \pm 0.67^{c}$ & $0.04 \pm 0.00 D^{e}$ & $0.02 \pm 0.00^{f g}$ & n.d. ${ }^{c}$ & $0.02 \pm 0.01^{g h}$ & n.d..$^{f}$ & $3.41 \pm 0.68^{c}$ \\
\hline \multirow[t]{3}{*}{$(1: 100)$} & 3 & $0.19 \pm 0.02^{\text {de }}$ & $0.002 \pm 0.00^{f}$ & $0.01 \pm 0.00^{g h}$ & $0.02 \pm 0.01^{\mathrm{b}}$ & $0.03 \pm 00.01^{g h}$ & $0.03 \pm 0.01^{f}$ & $0.28 \pm 0.04^{h}$ \\
\hline & 5 & $0.40 \pm 0.08^{\text {de }}$ & $0.002 \pm 0.00^{f}$ & $0.03 \pm 0.00^{f g}$ & $0.03 \pm 0.00^{\mathrm{a}}$ & $0.06 \pm 0.00^{\text {defg }}$ & $0.04 \pm 0.00^{f}$ & $0.56 \pm 0.09^{g h}$ \\
\hline & 10 & $0.29 \pm 0.02^{\text {de }}$ & n.d. ${ }^{f}$ & $0.03 \pm 0.01^{f}$ & $0.03 \pm 0.00^{\mathrm{a}}$ & $0.08 \pm 0.01^{\text {cde }}$ & n.d..$^{f}$ & $0.44 \pm 0.04^{g h}$ \\
\hline $\mathrm{CO}_{1}$ & 1 & $6.51 \pm 0.97^{a}$ & $0.05 \pm 0.01^{\mathrm{cd}}$ & $0.06 \pm 0.01^{e}$ & n.d. ${ }^{c}$ & $0.04 \pm 0.01^{\mathrm{gh}}$ & $0.77 \pm 0.08^{c}$ & $7.43 \pm 1.08^{a}$ \\
\hline \multirow[t]{3}{*}{$(1: 20)$} & 3 & $0.65 \pm 0.02^{d}$ & n.d. ${ }^{f}$ & $0.13 \pm 0.01^{\mathrm{a}}$ & n.d. ${ }^{c}$ & $0.04 \pm 0.01^{\text {fgh }}$ & $0.90 \pm 0.13^{b c}$ & $1.71 \pm 0.17^{d}$ \\
\hline & 5 & $0.49 \pm 0.09^{\text {de }}$ & $0.001 \pm 0.00^{f}$ & $0.04 \pm 0.01^{f}$ & n.d. ${ }^{c}$ & $0.02 \pm 0.00^{g h}$ & n.d..$^{f}$ & $0.54 \pm 0.11^{\mathrm{gh}}$ \\
\hline & 10 & $0.21 \pm 0.03^{\text {de }}$ & n.d. ${ }^{f}$ & n.d. ${ }^{h}$ & n.d. ${ }^{c}$ & $0.01 \pm 0.00^{h}$ & n.d..$^{f}$ & $0.22 \pm 0.03^{h}$ \\
\hline $\mathrm{CO}_{2}$ & 1 & $3.08 \pm 0.33^{c}$ & $0.04 \pm 0.01^{\text {cde }}$ & $0.03 \pm 0.01^{f}$ & n.d. ${ }^{c}$ & $0.02 \pm 0.01^{g h}$ & n.d..$^{f}$ & $3.18 \pm 0.35^{c}$ \\
\hline \multirow[t]{3}{*}{$(1: 100)$} & 3 & $0.24 \pm 0.02^{\text {de }}$ & n.d. ${ }^{f}$ & $0.06 \pm 0.01^{\mathrm{e}}$ & n.d. ${ }^{c}$ & $0.02 \pm 0.01^{\mathrm{gh}}$ & $0.33 \pm 0.06^{d}$ & $0.65 \pm 0.10^{g h}$ \\
\hline & 5 & $0.13 \pm 0.03^{\text {de }}$ & n.d. ${ }^{f}$ & n.d. ${ }^{\text {h }}$ & n.d. ${ }^{c}$ & $0.05 \pm 0.01^{\text {efgh }}$ & $0.37 \pm 0.02^{d}$ & $0.55 \pm 0.06^{\mathrm{gh}}$ \\
\hline & 10 & $0.14 \pm 0.03^{\mathrm{de}}$ & n.d. ${ }^{f}$ & n.d. ${ }^{\text {h }}$ & n.d. ${ }^{c}$ & $0.03 \pm 0.01^{g h}$ & $0.42 \pm 0.10^{d}$ & $0.58 \pm 0.13^{g h}$ \\
\hline
\end{tabular}

$C$ cholesterol $(50 \mathrm{mg}), L$ linoleic acid, $O$ oleic acid, $C L_{1}$ cholesterol $(50 \mathrm{mg})$ : linoleic acid $(1 \mathrm{~g})=1: 20, C L_{2}$ cholesterol $(50 \mathrm{mg}):$ linoleic acid $(5 \mathrm{~g})=1: 100, C O_{1}$ : cholesterol $(50 \mathrm{mg})$ : oleic acid $(1 \mathrm{~g})=1: 20, \mathrm{CO}_{2}$ cholesterol $(50 \mathrm{mg})$ : oleic acid $(5 \mathrm{~g})=1: 100$

$7 \beta-\mathrm{OH} 7 \beta$-hydroxycholesterol, 20a-OH 7a-hydroxy-cholesterol, 25-OH 25-hydroxycholesterol, Triol Cholestanetriol, a-epoxide 56a-epoxycholesterol, 7-keto 7-ketocholesterol

${ }^{* * *} P<0.001$, n.d not detected

${ }^{\mathrm{a}-\mathrm{h}}$ Means \pm SE with different superscript in the same column differ significantly

various heating times $(\mathrm{P}<0.001)$, and 7 -keto was the sole COP observed when the sample was heated at $200{ }^{\circ} \mathrm{C}$. These results agree with those reported by Osada et al. [26], which revealed that 7-keto was the most predominant oxidized cholesterol produced when cholesterol was heated in the presence of different fats. The levels of $20 \alpha-\mathrm{OH}$ were higher in samples heated for $1 \mathrm{~h}$ than in those heated for longer times $(3,5$ and $10 \mathrm{~h}$ ) at $200{ }^{\circ} \mathrm{C}$. The levels of $25-\mathrm{OH}, \alpha$-epoxide, and 7keto in samples containing linoleic acid $\left(\mathrm{CL}_{1}\right.$ and $\left.\mathrm{CL}_{2}\right)$ gradually increased as the heating time increased, and a similar result was observed for 7-keto in the $\mathrm{CO}_{2}$ samples. Bascoul et al. [27] reported that the presence of unsaturated fatty acids in tallow accelerated the formation of oxidized cholesterol compared to when cholesterol alone was heated [28]. These results reflect that unsaturated fatty acids are not resistant to oxidation.

The data presented in Tables 3, 4, and 5 depict the total amounts of COPs generated in cholesterol samples with or without unsaturated fatty acids heated at 100,150 , and $200{ }^{\circ} \mathrm{C}$ for 1 to $10 \mathrm{~h}$. The production rate of COPs was $0.01-8.25 \%$, higher in cholesterol samples with added unsaturated fatty acids than that in cholesterol samples without unsaturated fatty acids (control). When heated at $150{ }^{\circ} \mathrm{C}$ or $200{ }^{\circ} \mathrm{C}$, the amounts of COPs generated were higher in cholesterol samples with linoleic acid than in those with oleic acid. The highest level of COPs produced in samples heated at $150{ }^{\circ} \mathrm{C}$ for $10 \mathrm{~h}$ was $2.60 \mathrm{mg}$, while samples heated at $200{ }^{\circ} \mathrm{C}$ for $1 \mathrm{~h}$ produced $7.43 \mathrm{mg}$ of COPs. Al-Saghir et al. [29] assessed the lipid quality and degree of cholesterol oxidation under different cooking conditions, PUFA was oxidized when heated at high temperatures and consequently produced radicals that oxidize cholesterol. Osada et al. [26] reported that autoxidation of cholesterol may occur in shorter time periods when heated above $120{ }^{\circ} \mathrm{C}$. This indicates that COP production is accelerated during heating at relatively high temperatures in shorter time periods. In addition, SotoRodriguez et al. [30] observed levels of cholesterol oxidation products ranging from 4.5 to $5.7 \mathrm{mg} / 100 \mathrm{~g}$ in Mexican fried products. These results suggest that the degree of unsaturation of fatty acids affects cholesterol oxidation. PUFAs, especially $n-3$ PUFA, are attractive 
compounds to incorporate into functional food, but they are difficult to protect from lipid peroxidation processes. Saldanha and Bragagnolo [31] stated that the amount of PUFA and the grilling temperature both increase the production of cholesterol oxides. Further, the extent of oxidation depends on the composition of fatty acids and minor compounds [32]. We concluded from this study that the temperature affects the rate of cholesterol oxidation and that higher temperatures increase the rates of COP production. Ansorena et al. [33] observed that at $180{ }^{\circ} \mathrm{C}$, the oxidation of unsaturated triglycerides occurs prior to the oxidation of cholesterol and saturated fatty acids. However, the authors reported a contradictory conclusion in which the presence of a lipid matrix increasingly inhibits cholesterol oxidation as the degree of saturation increases.

\section{COP formation in model systems}

The linear, quadratic, and interaction coefficients for COP formation in model systems were calculated (data not shown). The coefficients of determination $\left(R^{2}\right)$ varied from
0.31 to 0.93 for the total amounts of COPs (0.93), 7keto (0.91), $\alpha$-epoxide (0.88), 25-OH (0.58), 20 $\alpha-\mathrm{OH}$ (0.49), triol (0.41), and 7 $\beta-\mathrm{OH}(0.31)$. From the $\mathrm{R}^{2}$ value of all the COPs, it is evident that strong correlations exist between the heating conditions and COP production, particularly for 7-keto and a-epoxide. Figure 1a shows the response surface 3D mesh plot which illustrates the total amounts of COPs generated under different heating conditions. The production rates of the COPs increased as the heating temperatures were increased, particularly when samples were heated at relatively high temperatures for short time periods. These findings agree with those reported by Osada et al. [26]: heating samples above $120{ }^{\circ} \mathrm{C}$ resulted in cholesterol autoxidation in shorter time periods. Cholesterol was converted to COPs during heating and residual cholesterol decreased as cholesterol oxidation increased. These findings of this study are consistent with the results reported by Chien et al. [24]: the authors stated that the percentage of cholesterol changed when samples were heated at $140{ }^{\circ} \mathrm{C}$ for up to $2 \mathrm{~h}$. Further, $16.2 \%$ of cholesterol

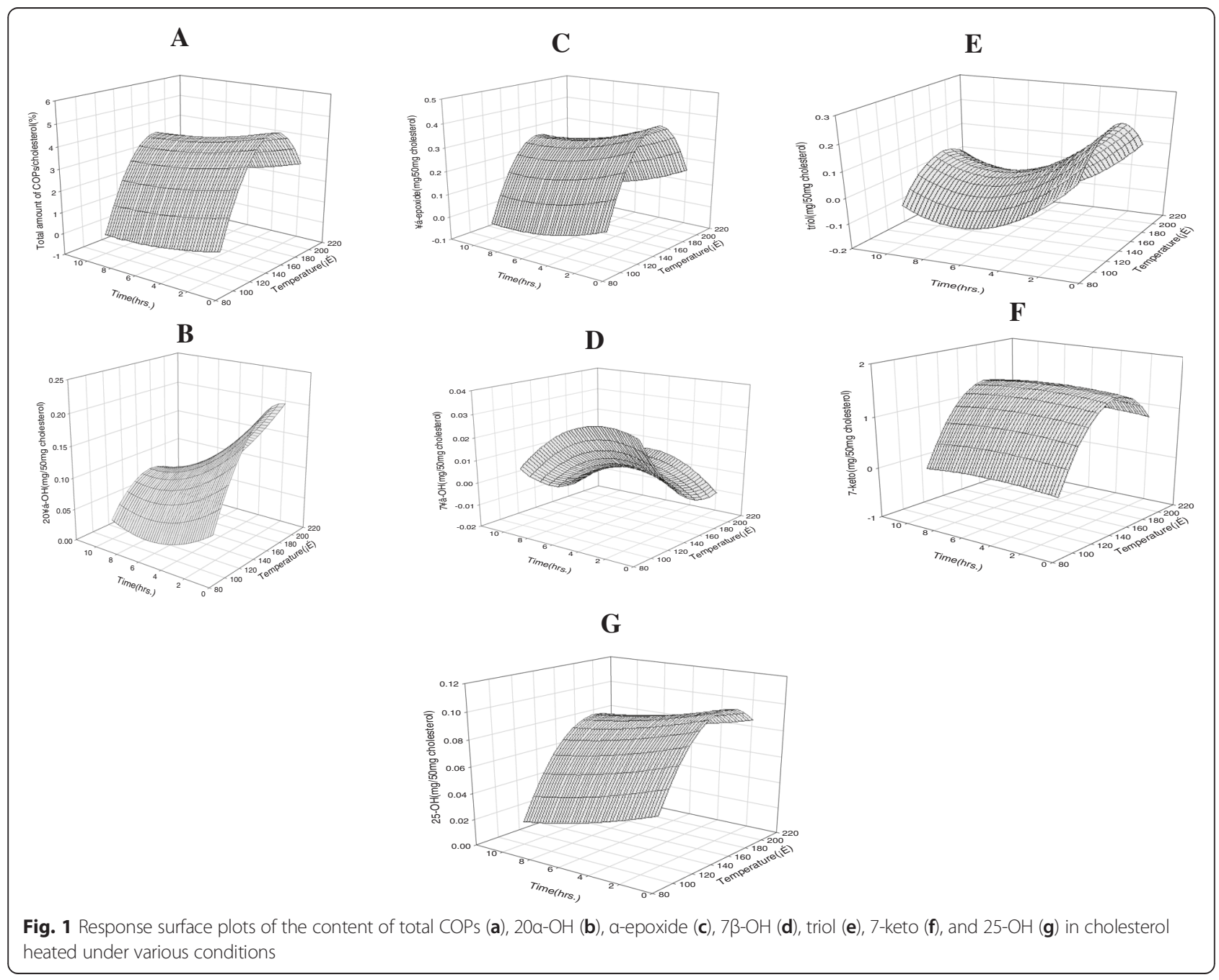


was lost after $40 \mathrm{~min}$ of heating and a loss of $86.3 \%$ occurred after heating for $2 \mathrm{~h}$. Zhang [34] also reported a loss of less than $30 \%$ and $70 \%$ of cholesterol after 30 min of heating at $125{ }^{\circ} \mathrm{C}$ and $150{ }^{\circ} \mathrm{C}$, respectively. Zardetto et al. [35] studied the formation of COPs in the thermal processing of fresh egg pasta and observed that the total level of COPs increased with both increasing heat treatment and heating time.

The response surface 3D mesh plots corresponding to the amounts of $20 \alpha-\mathrm{OH}, \alpha$-epoxide, $7 \beta-\mathrm{OH}$, triol, 7-keto, and 25-OH are shown in Fig 1(b-g). High heating temperatures and short heating times resulted in high amounts of $20 \alpha-\mathrm{OH}$ in cholesterol (Fig. 1b) and $\alpha$-epoxide (Fig. 1c). Similar results were reported by Chien et al. [24] that cholesterol oxidation in the solvent system was too fast to be monitored at $160{ }^{\circ} \mathrm{C}$ and at higher temperatures. Similarly, $\alpha$-epoxide and $\beta$ epoxide cholesterol may undergo alcoholysis in aqueous media to form cholestane-triol. Chien et al. [25] also observed epoxide formation during an initial period of heating at $150{ }^{\circ} \mathrm{C}$. The amount of $7 \beta-\mathrm{OH}$ generated was high at a low heating temperature and moderate heating time (Fig. 1d). Additionally, the highest level of triol was produced from short heating times (below $2 \mathrm{~h}$ ) at moderate heating temperatures ranging from $150-170{ }^{\circ} \mathrm{C}$ (Fig. 1e). Further, 7-keto (Fig. 1f) was mainly produced at high temperatures $\left(180-200{ }^{\circ} \mathrm{C}\right)$ throughout all heating times $(1,3,5$ and $10 \mathrm{~h})$. In the case of $25-\mathrm{OH}$, its production gradually increased as the heating time increased (Fig. 1g). These results support findings from previously reported studies [25] in which the percentage of $7-\mathrm{OH}$ ( $7 \alpha-\mathrm{OH}$ and $7 \beta-\mathrm{OH})$ also increased sharply during the first $10 \mathrm{~min}$ of heating at $150{ }^{\circ} \mathrm{C}$ and reached a plateau thereafter. Further, a report by Zhang [34] illustrated the changing levels of 7-ketocholesterol when cholesterol was heated at different temperatures and times. For example, 7-ketocholesterol was not detected even after cholesterol had been heated at $125^{\circ} \mathrm{C}$ for $30 \mathrm{~min}$. However, 7-ketocholesterol was detected when the heating temperature was raised to $150{ }^{\circ} \mathrm{C}$. The concentration of 7-ketocholesterol drastically increased to $2.11 \mu \mathrm{g} / \mathrm{mL}$ during $30 \mathrm{~min}$ of heating at $150{ }^{\circ} \mathrm{C}$. When heated at $175{ }^{\circ} \mathrm{C}$, the concentration rapidly increased to $2.06 \mu \mathrm{g} / \mathrm{mL}$ within $10 \mathrm{~min}$ and then leveled off. After 10 min of heating at $200{ }^{\circ} \mathrm{C}$, the 7-ketocholesterol concentration increased continuously and production of 7 ketocholesterol did not correspond to a loss of cholesterol at $200{ }^{\circ} \mathrm{C}$. The rate of cholesterol degradation at $200{ }^{\circ} \mathrm{C}$ was lower than the rate of 7-ketocholesterol production after $10 \mathrm{~min}$ of heating. Kamal-Eldin [32] reported the effects of temperature on the oxidation of flaxseed oil and observed the following trends: long induction periods at low temperatures $\left(<84{ }^{\circ} \mathrm{C}\right)$, shorter induction periods at intermediate temperature ranges $\left(84-130{ }^{\circ} \mathrm{C}\right)$, and no induction periods at high temperatures $\left(>130{ }^{\circ} \mathrm{C}\right)$. In the current study, it is evident from the $3 \mathrm{D}$ surface response plots that $\mathrm{COP}$ production increases with increasing temperature, except in the cases of $7 \beta-\mathrm{OH}$ and triol, which increase in production at moderate temperatures; higher temperatures decrease the production levels of $7 \beta-\mathrm{OH}$ and triol.

\section{Conclusions}

Cholesterol oxidation was studied at different heating temperatures and heating times in model systems with controlled $\mathrm{pH}$ levels and added unsaturated fatty acids. The results revealed increased cholesterol oxidation at low $\mathrm{pH}$ levels and in the presence of either linoleic or oleic acid. The oxidation of unsaturated fatty acid was highest from $1 \mathrm{~h}$ of heating, whereas longer heating times resulted in a decrease in cholesterol oxidation. Moreover, the rates of COP production increased as the heating temperatures increased, particularly during shorter heating times. Finally, a heating temperature of $150{ }^{\circ} \mathrm{C}$ resulted in maximum cholesterol oxidation and COP production in the model systems.

\section{Abbreviations \\ COPs: Cholesterol oxidation products; UFA: Unsaturated fatty acid; PUFA: Polyunsaturated fatty acid; BHT: Butylated hydroxyl toluene; GC: Gas

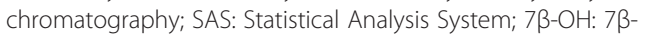 hydroxycholesterol; 20a-OH: 7a-hydroxy-cholesterol; 25-OH: 25- hydroxycholesterol; Triol: Cholestanetriol; a-epoxide: 5,6a-epoxycholesterol; 7- keto: 7-ketocholesterol.}

\section{Competing interests}

The authors declare that they have no competing interests.

\section{Authors' contributions}

The contribution of each authors to have this manuscript are as follow: JSM and SOL has planed the study design, conduct study analyses and prepared preliminary manuscript. MIK analyze the data and proofed the manuscript to its final shape. DGY and KHS conducted the analysis of sample for COPS. ML assisted in statistical analysis of data and experimental designing. CJ provide technical assistance during experiment, provide funding for experiments and help in manuscript preparation.. It is confirmed that all authors have read the manuscript and approve its final version for submission.

\section{Acknowledgements}

This work was supported from Radiation Technology R\&D program (NRF-2014M2A2A6045051) through the National Research Foundation of Korea funded by the Ministry of Science, ICT \& Future Planning and partially from Institute of Green Bio Science and Technology, Seoul National University.

\section{Author details}

${ }^{1}$ CJ Food Research Center, Seoul 152-050, Korea. ${ }^{2}$ Department of Agricultural Biotechnology, Center for Food and Bioconvergence, and Research Institute of Agriculture and Life Science, Seoul National University, Seoul 51-921, Korea. ${ }^{3}$ National Institute of Food Science and Technology, University of Agriculture, Faisalabad 38040, Pakistan. ${ }^{4}$ Department of Health

Administration and Food Hygiene, Jinju Health College, Jinju 660-757, Korea. ${ }^{5}$ National Institute of Animal Science, RDA, Cheonan 331-801, Korea.

Received: 12 March 2015 Accepted: 7 July 2015

Published online: 23 July 2015 


\section{References}

1. Addis PB. Occurrence of lipid oxidation products in foods. Food Chem Toxicol. 1986;24:1021-30

2. Lund $\mathrm{E}$, Bjorkhem I. Down-regulation of hepatic HMG-CoA reductase in mice by dietary cholesterol: importance of the delta 5 double bond and evidence that oxidation at C-3, C-5, C-6 or C-7 is not involved. Biochem. 1994;33:291-7

3. Peng SK, Hu B, Morin R. Angiotoxicity and atherogenicity of cholesterol oxides. J Clin Lab Anal. 1991;5:144-52.

4. Ryan E, Chopra J, McCarthy F, Maguire AR, O'Brien NM. Qualitative and quantitative comparison of the cytotoxic and apoptotic potential of phytosterol oxidation products with their corresponding cholesterol oxidation products. Brit J Nutr. 2005;94:443-51.

5. Savage GP, Dutta P, Rodri'guez-Estrada MT. Cholesterol oxides: their occurrence and methods to prevent their generation in foods. Asia Pacific J Clin Nutr. 2002;11:72-8.

6. Linseisen J, Wolfram G. Origin, metabolism and adverse health effects of cholesterol oxidation products. Fett-Lipid. 1998;100:211-8.

7. Lee SO, Lim DG, Seol KH, Erwanto Y, Lee M. Effects of various cooking and re-heating methods on cholesterol oxidation products of beef loin. Asian Australas J Anim Sci. 2006;19:756-62.

8. McCluskey S, Connolly JF, Devery R, O'Brien B, Kelly J, Harrington D, et al. Lipid and cholesterol oxidation in whole milk powder during processing and storage. J Food Sci. 1997;62:331-7.

9. Conchillo A, Ansoreno D, Astiasaran I. Intensity of lipid oxidation and formation of cholesterol oxidation products during frozen storage of raw and cooked chicken. J Sci Food Agric. 2005;85:141-6.

10. Lee Jl, Kang S, Ahn DU, Lee M. Formation of cholesterol oxides in irradiated raw and cooked chicken meat during storage. Poultry Sci. 2001;80:105-8.

11. Hsieh FJ, Kinsella JE. In Oxidation of Polyunsaturated Fatty Acid: Mechanism, Products, and Inhibition with Emphasis on Fish. New York: Academic; 1987. p. 233-341.

12. Suechin $X L$, Geetha $C$, Dong UA, Robert TH, Jeong SS. Storage, heating, and tocopherols affect cholesterol oxide formation in food oils. J Agric Food Chem. 1996;44:3830-4.

13. Saldanha T, Benassib MT, Bragagnolo N. Fatty acid contents evolution and cholesterol oxides formation in Brazilian sardines (Sardinella brasiliensis) as a result of frozen storage followed by grilling. LWT-Food Sci Technol. 2008:41:1301-9.

14. Miyako K, Terao J, Matsushita S. Phospholipid oxidation catalyzed by ferrous ion and ascorbic acid. Agric Biol Chem. 1984;48:1275-9.

15. Gontard N, Guilbert S, Cuq JL. Edible wheat gluten films: Influence of the main process variables on film properties using response surface methodology. J Food Sci. 1992;57:190-6.

16. King VAE, Zall RR. A response surface methodology approach to the optimization of controlled low-temperature vacuum dehydration. Food Res Int. 1992;25:1-8.

17. Niki E, Yoshida Y, Saito Y, Noguchi N. Lipid peroxidation: mechanisms, inhibition, and biological effects. Biochem Biophys Res Comm. 2005;336:1-9.

18. Chien JT, Hsu DJ, Chen BH. Kinetic model for studying the effect of quercetin on cholesterol oxidation during heating. J Agric Food Chem. 2006;54:1486-92.

19. Juncher D, Rhon B, Mortensen ET, Henckel P, Karisson A, Skibsted LH, et al. Effect of pre-slaughter physiological conditions on the oxidative stability of colour and lipid during chill storage of pork meat. Meat Sci. 2001;58:347-57.

20. Yasosky JJ, Aberle ED, Peng IC, Mills EW, Judge MD. Effects of pH and time of grinding on lipid oxidation of fresh ground pork. J Food Sci. 1984;49:1510-2.

21. Andersen HJ, Bertelsen G, Skibsted LH. Salt effect on acid-catalyzed autoxidation of oxymyoglobin. Acta Chemica Scandinavia A. 1988:42:226-36.

22. Buckley DJ, Gray JI, Ashgar A, Price JF, Crackle RL, Booren AM, et al. Effects of dietary antioxidants and oxidized oil on membranal lipid stability and pork product quality. J Food Sci. 1989;54:1193-7.

23. Kowale BN, Rae VK, Babu NP, Sharma N, Bisht GS. Lipid oxidation and cholesterol oxidation in mutton during cooking and storage. Meat Sci. 1996;43:195-202.

24. Chien JT, Huang DY, Chen BH. Kinetic studies of cholesterol oxidation as inhibited by stearylamine during heating. J Agric Food Chem. 2004:52:7132-1738.
25. Chien JT, Wang HC, Chen BH. Kinetic model of the cholesterol oxidation during heating. J Agric Food Chem. 1998;46:2572-7.

26. Osada K, Kodama T, Yamada K, Sugano M. Oxidation of cholesterol by heating. J Agric Food Chem. 1993;41:1198-202.

27. Bascoul J, Domergue N, Olle M, Crastes de Paulet A. Autoxidation of cholesterol in tallows heated under deep frying condition: evaluation of oxysterols by GLC and TLC-FID. Lipids. 1986;21:383-7.

28. Nawar WW, Kim SK, Li YJ, Vajdi M. Measurement of oxidative interactions of cholesterol. J Am Oil Chem Soc. 1991;68:496-8.

29. Al-Saghir S, Thurner K, Wagner KH, Frisch G, Luf W, Razzazi-Fazeli E, et al. Effects of different cooking procedures on lipid quality and cholesterol oxidation of farmed salmon fish (Salmo salar). J Agric Food Chem. 2004;52:5290-6.

30. Soto-Rodriguez I, Campillo-Velazquez PJ, Ortega-Martınez J, Rodrıguez-Estrada MT, Lercker G, Garcia HS. Cholesterol oxidation in traditional Mexican dried and deep-fried food products. J Food Comp Anal. 2008;21:489-95.

31. Saldanha T, Bragagnolo N. Cholesterol Oxidation is Increased and PUFA Decreased by Frozen Storage and Grilling of Atlantic Hake Fillets (Merluccius hubbsi). Lipids. 2007:42:671-8.

32. Kamal-Eldin A, Yanishlieva NV. N-3 fatty acids for human nutrition: stability considerations. Eur J Lipid Sci Technol. 2002;104:825-36.

33. Ansorena D, Barriuso B, Cardenia V, Astiasaran I, Lercker G, Rodriguez-Estrada MT. Thermo-oxidation of cholesterol: Effect of the unsaturation degree of the lipid matrix. Food Chem. 2013;141:2557-764.

34. Zhang T. Cholesterol oxidation in roasted salmon fish with different cooking oils. In: A Thesis, Graduate Faculty of The Louisiana State University and Agricultural and Mechanical College. 2005.

35. Zardetto S, Barbanti D, Rosa MD. Formation of cholesterol oxidation products (COPs) and loss of cholesterol in fresh egg pasta as a function of thermal treatment processing. Food Res Int. 2014;62:177-82.

\section{Submit your next manuscript to BioMed Central and take full advantage of:}

- Convenient online submission

- Thorough peer review

- No space constraints or color figure charges

- Immediate publication on acceptance

- Inclusion in PubMed, CAS, Scopus and Google Scholar

- Research which is freely available for redistribution 